\title{
Flexural strength and tribological properties of rare earth treated short carbon fiber/polyimide composites
}

\author{
X. R. Zhang1,2, P. Zhao ${ }^{1}$, X. Q. Pei ${ }^{1}$, Q. H. Wang ${ }^{*}$, Q. Jia ${ }^{1}$ \\ ${ }^{1}$ State Key Laboratory of Solid Lubrication, Lanzhou Institute of Chemical Physics, Chinese Academy of Sciences, \\ Lanzhou 730000, China \\ ${ }^{2}$ Graduate School, Chinese Academy of Sciences, Beijing 100039, China
}

Received 21 June 2007; accepted in revised form 8 August 2007

\begin{abstract}
To investigate the influence of carbon fiber (CF) surface treatment on the flexural strength and tribological properties of the short-cut $\mathrm{CF}$ /polyimide (PI) composites, pitch-based short-cut $\mathrm{CF}$ were treated by rare earth. The $\mathrm{CF}$ before and after treatment was examined by X-ray photoelectron spectroscopy (XPS) and by scanning electron microscopy (SEM). The flexural strength of the specimens was determined in a three-point test machine. The friction and wear behaviors of PI composites sliding against GCr15 steel rings were evaluated on an M-2000 model ring-on-block test rig. The results show that the surface of the treated $\mathrm{CF}$ became rougher and there formed lots of active groups after rare earth treatment. The flexural strength of PI composites with rare earth treated CF was improved. The friction coefficient and wear rate of PI composites with rare earth treated CF were lower than that with untreated CF.
\end{abstract}

Keywords: polymer composites, carbon fiber, surface treatment, flexural strength, tribological property

\section{Introduction}

PI possesses some extraordinary characteristics, such as excellent mechanical and electrical (insulating) properties, good thermal stability and chemical inertness, high wear resistance, and resistance against high energy radiation $[1,2]$. Yet, it can not be widely used as self-lubricant material because of its high friction coefficient. Therefore, various fillers have been tried to modify PI composites. CF are widely used as fillers in advanced composite materials due to their high strength and high modulus, excellent electrical and thermal conductivity, good friction and wear qualities and high resistance to fatigue and creep $[3,4]$. The CF filled PI composites have especial application in aerospace, robots, sports goods. By reinforcing PI with CF of high strength and modulus, it might be feasible to develop high performance PI-based composites.
The properties of fiber and matrix make a critical contribution to the quality of a fiber-reinforced composite. In addition, the physical-chemical interaction between the fiber-matrix interface plays an important role in improving the mechanical properties of the fiber reinforced composite [4]. CF are chemically inert and they often produce composites with low interfacial bonding between fibers and matrix when used without any surface treatment, which accordingly affects most of the other mechanical properties of the composites [5]. Numerous methods concerning surface treatment, such as chemical method [6-8], electrochemical method [9-12], plasma treatment [13], etc., have been developed to modify the fiber surface and thus enhance the ability to establish strong interactions between fibers and matrix. Rare earth treatment is relatively novel and interesting method, which have attracted more and more researchers' interest. 
Our previous work found the optimum content of $\mathrm{CF}$ in PI composite was $15 \mathrm{wt} \%$ [14]. In this work, rare earth treatment was applied to modify the $\mathrm{CF}$ surface, and its effect on the flexural strength and tribological properties of PI composites was evaluated.

\section{Experimental}

\subsection{Materials and preparation of PI composites}

PI (YS-20) powders $(<38 \mu \mathrm{m})$ were commercially obtained from Shanghai Synthetic Resin Institute (Shanghai, China). The short-cut carbon fiber was about $1.5 \mathrm{~mm}$ in length and $7.8 \mu \mathrm{m}$ in diameter, and the density was about $1.8 \mathrm{~g} / \mathrm{cm}^{3}$. The commercial short-cut carbon fibers were dipped in acetone for $24 \mathrm{~h}$, then cleaned ultrasonically with acetone for $0.5 \mathrm{~h}$. Finally, they were dried at $100^{\circ} \mathrm{C}$ for 5 hours before used.

As for the rare earth treatment, carbon fibers were soaked in an alcoholic solution of $\mathrm{LaCl}_{3}$ for $5 \mathrm{~h}$. the $\mathrm{LaCl}_{3}$ content in the alcoholic solution was $0.3 \mathrm{wt} \%$. The content of CF in PI composite was $15 \mathrm{wt} \%$, the untreated and rare earth treated $\mathrm{CF}$ were mixed with PI powders to prepare mixtures for the preparation of PI composites. The temperature program of moulding is shown in Figure 1. At the end of each run of compression sintering, the resulting specimens were cooled with the stove in air, cut into pre-set sizes for flexural strength and tribological properties tests.

In order to investigate the possible change of chemical composition of CF treated by rare earth, XPS was used to detect functionalities on activated carbon fibers surfaces. The XPS measurement was performed using VG Scientific ESCA LAB 210

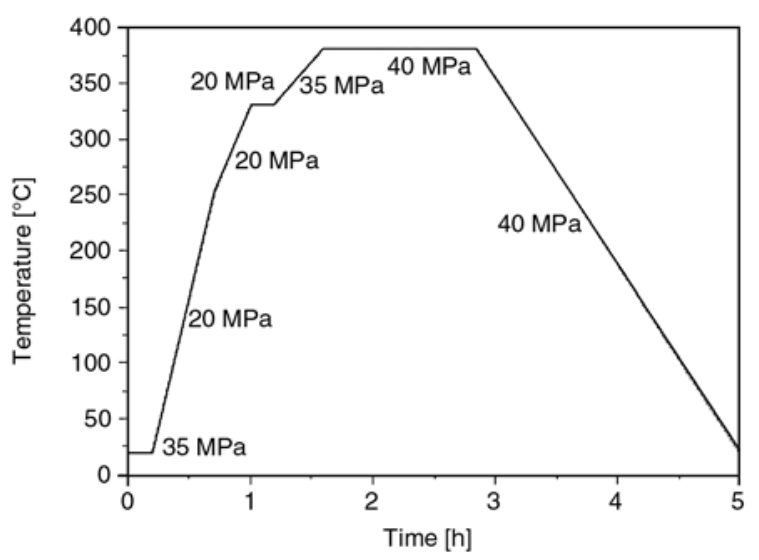

Figure 1. The temperature program of moulding spectrometer, the base pressure in the sample chamber was about $10^{-7} \mathrm{~Pa}$. The morphologies of the treated and untreated CF were compared by SEM observation, before which the tested CF specimens were plated with gold coating to render them electrically conductive.

\subsection{Flexual strength test}

The flexural strength of the specimens was determined in a three-point test machine (DY35 Universal material tester, France) with a span of $40 \mathrm{~mm}$ and crosshead speed of $1 \mathrm{~mm} / \mathrm{min}$. The specimens were $65 \mathrm{~mm} \times 7 \mathrm{~mm} \times 3 \mathrm{~mm}$ and the test surface was $65 \mathrm{~mm} \times 7 \mathrm{~mm}$. Three specimens of each PI composites were measured and an average value was reported. The specific flexural strength $\left(\sigma_{f}\right)$ of the specimen was calculated from Equation (1):

$$
\sigma_{f}=\frac{3 P \cdot l}{2 b \cdot h^{2}} \quad[\mathrm{MPa}]
$$

where $P$ is the maximum load $[\mathrm{N}], l$ is the span length [mm], $b$ is the width of the specimen [mm], $h$ is the thickness of the specimen [mm].

\subsection{Tribological properties test}

The friction and wear behaviors of PI composites sliding against stainless steel were evaluated on an M-2000 model ring-on-block test rig (made by Jinan Testing Machine Factory, China).The contact schematic diagram is shown in Figure 2, the blocks in a size of $30 \mathrm{~mm} \times 7 \mathrm{~mm} \times 6 \mathrm{~mm}$ were made of the PI composites, the rings of $\varnothing 40 \mathrm{~mm} \times 16 \mathrm{~mm}$ were made of GCr15 stainless steel, the chemical composition of the GCr15 bearing steel (mass fraction, \%) is shown in Table 1 . The tests were carried

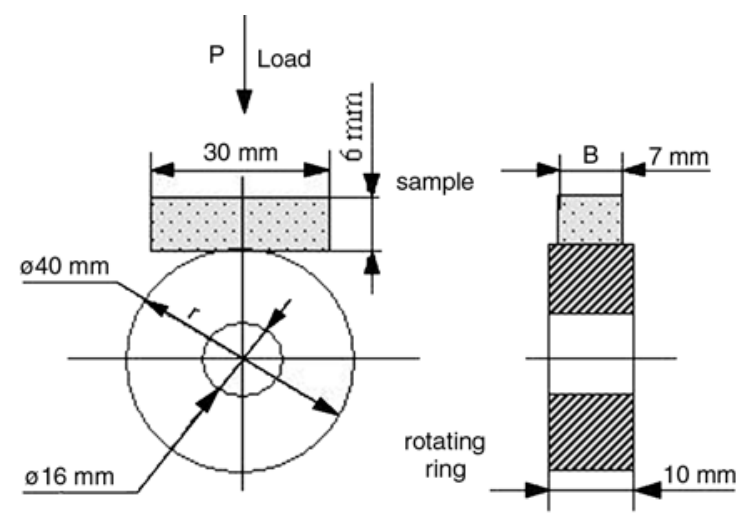

Figure 2. The contact schematic diagram for the friction couple 
Table 1. Chemical composition of the GCr15 steel ring

\begin{tabular}{|c|c|c|c|c|c|}
\hline \multicolumn{5}{|c|}{ Chemical composition (mass fraction, \%) } \\
\hline C & Mn & Si & P & S & Cr \\
\hline $0.95-1.05$ & $0.25-0.45$ & $0.15-0.35$ & $\leq 0.025$ & $\geq 0.025$ & $1.40-1.65$ \\
\hline
\end{tabular}

out at a linear velocity of $0.431 \mathrm{~m} / \mathrm{s}$ in a period of 120 min with the loads of $200 \mathrm{~N}$. Before each test, the stainless steel ring and the PI composite block were polished to a roughness $\left(R_{a}\right)$ of about $0.2-$ $0.3 \mu \mathrm{m}$. The block specimen was static and the GCr15 bearing was sliding against the block unidirectionally. The friction force was measured using a torque shaft equipped with strain gauges mounted on a vertical arm that carried the block, which was used to calculate the friction coefficient by taking into account the normal load applied. The width of the wear tracks was measured with a reading microscope to an accuracy of $0.01 \mathrm{~mm}$. Then the specific wear rate $(\omega)$ of the specimen was calculated from Equation (2):

$\omega=\frac{B}{L \cdot P}\left[\frac{\pi r^{2}}{180} \arcsin \left(\frac{b}{2 r}\right)-\frac{b}{2 r} \sqrt{r^{2}-\frac{b^{2}}{2}}\right]$

$$
\left[\mathrm{mm}^{3} / \mathrm{N} \cdot \mathrm{m}\right]
$$

where $B$ is the width of the specimen [mm], $r$ is the semi diameter of the stainless steel ring $[\mathrm{mm}]$, and $b$ is the width of the wear trace [mm], $L$ is the sliding distance in meter, $P$ is the load in Newton. The tests were repeated for three times, the wear tracks of the composite and stainless steel specimens were examined on a JSM- 5600LV scanning electron microscope (SEM). In order to increase the resolution for the SEM observation, the tested composite specimens were plated with gold coating to render them electrically conductive.

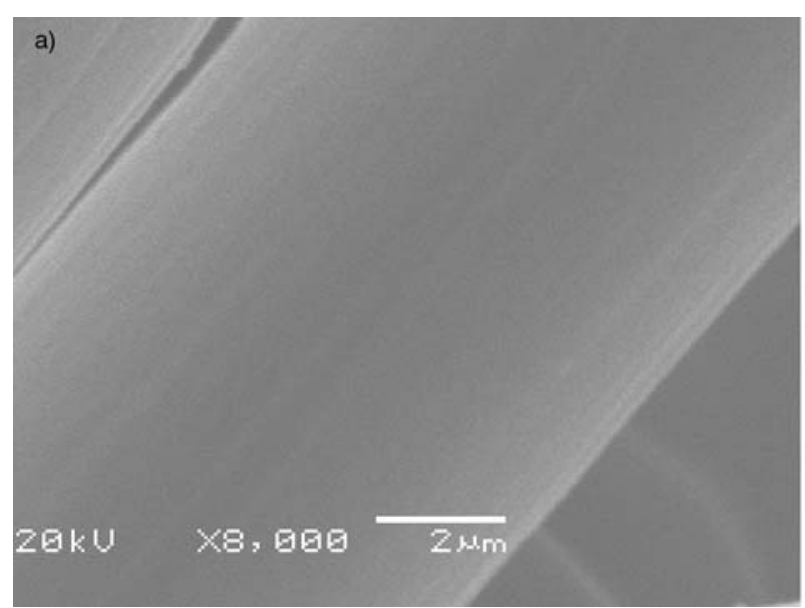

\section{Results and discussion}

\subsection{Morphology analysis}

The SEM morphologies of the untreated and rare earth treated CF are shown in Figure 3. The surface of the untreated CF (Figure 3a) seems to be relatively smooth and the grooves were less obvious. The surface of the rare earth treated CF (Figure 3b) became rougher and there appeared more etched ridges with newly grooves and protuberances. The $\mathrm{LaCl}_{3}$ solution can etch the surface of carbon fibers thus increased the surface roughness. The surface became rougher after rare earth treatment, i. e. the fibers possessed a larger surface area, which could contact with PI matrix and thus formed more mechanical interlocking sites. The mechanical interlocking provided a strong interface bonding even though other effects were relatively weak [15]. In addition, the enhancement of the surface roughness reduced the contact angle between fibers and PI and hence increased the wettability [16].

\subsection{XPS analysis}

The overall XPS spectra of different samples are shown in Figure 4. It can be observed that the fiber surfaces consisted mainly of carbon as indicated by the intense $\mathrm{C} 1 \mathrm{~s}$ peak at approximately $285 \mathrm{eV}$. In addition, a considerable amount of oxygen could be found by the $\mathrm{O} 1 \mathrm{~s}$ peak at approximately $533 \mathrm{eV}$, which varied to a certain extent with the different of treatment. The element information got from the XPS spectra is shown in Table 2. It can be found that the surface $\mathrm{C}$ element concentration of the untreated, rare earth treated $\mathrm{CF}$ samples were $84.5 \%, 81.7 \%$ respectively. A lower C concentration was found on the surfaces of the rare earth

Figure 3. SEM morphologies of the untreated (a) and rare earth treated (b) CF 


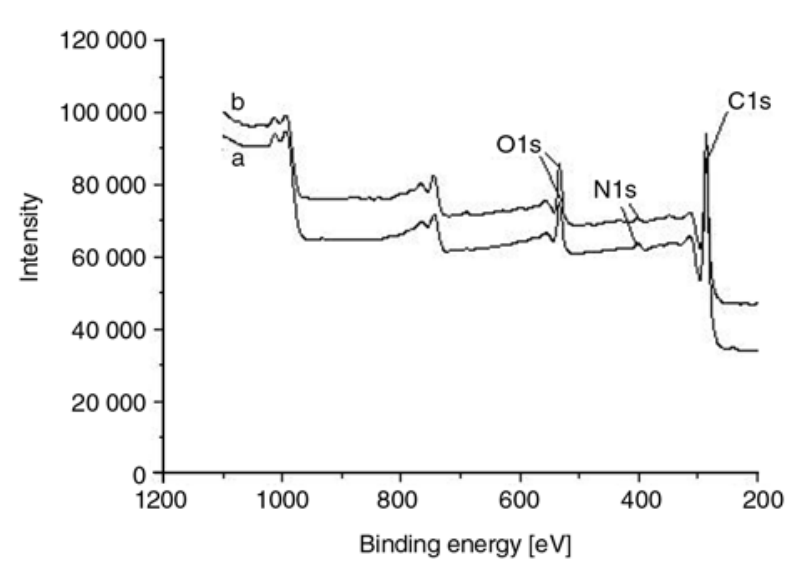

Figure 4. Overall XPS spectra of different samples: Untreated CF (a); Rare earth treated CF(b)

Table 2. XPS surface element analysis data of CF and rare earth treated $\mathrm{CF}$

\begin{tabular}{|l|c|c|c|}
\hline \multicolumn{1}{|c|}{ Samples } & C [\%] & O [\%] & O/C [\%] \\
\hline CF & 84.5 & 15.5 & 18.3 \\
\hline Rare earth treated CF & 81.7 & 18.3 & 22.4 \\
\hline
\end{tabular}

treated CF sample compared with that of the untreated one. The surface $\mathrm{O}$ concentration of the untreated, rare earth treated $\mathrm{CF}$ samples were $15.5 \%, 18.3 \%$, respectively. The number of functional groups for untreated CF sample was attributed to the residual groups of the polymeric precursor, polyacrylonitrile and the polymeric sizing on the $\mathrm{CF}$ after washing in acetone with ultrasound. $\mathrm{La}^{3+}$ has high electronegativity thus has great oxidative ability, more new-formed oxygencontained groups can form on the surface when CF was soaked in rare earth solution, which resulted in an increase in oxygen content as well as the O/C ratio.

The curve fitting spectra of $\mathrm{C} 1 \mathrm{~s}$ of the untreated and rare earth treated CF is revealed in Figure 5. The main $\mathrm{C} 1 \mathrm{~s}$ peak is presented at $285 \mathrm{eV}$, which correspond to the graphitic linkage of carbon fiber. In addition, there are some peaks appeared at the higher binding energy positions compared with the main $\mathrm{C}$ 1s peak and they correspond to different oxygen-containing groups. Table 3 gives the different oxygen-contained carbon structural components possibly existed on CF. Each functional group gives rise to a signal in the XPS spectrum with a particular range of binding energies.

According to Table 3, the fitting results of $\mathrm{C} 1 \mathrm{~s}$ of different samples are shown in Table 4. It is noted that the $\mathrm{C} 1 \mathrm{~s}$ spectra included another three peaks except main 'graphitic' peak at $285 \mathrm{eV}$. After rare
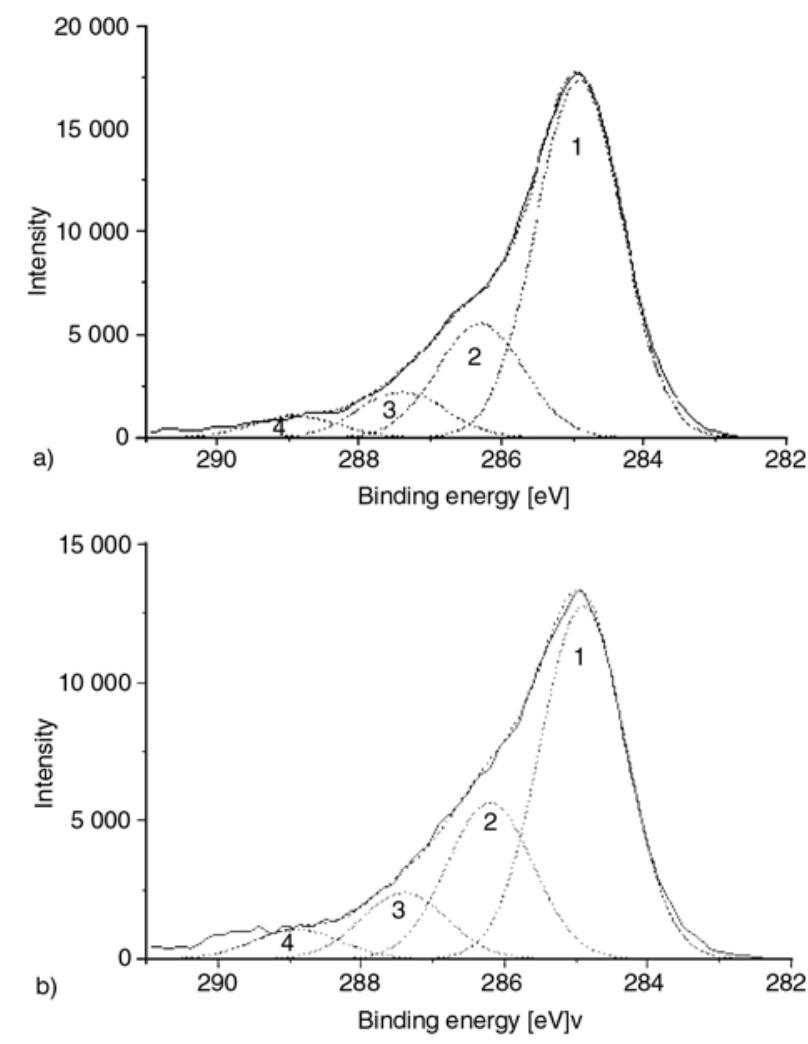

Figure 5. Curve fitting spectra of $\mathrm{C} 1 \mathrm{~s}$ of the untreated (a) and rare earth treated (b) CF samples

Table 3. Component peak positions used in $\mathrm{C} 1$ s curve fitting

\begin{tabular}{|c|c|c|}
\hline Peak no. & Functionality & Binding energy [eV] \\
\hline 1 & $-\mathrm{C}-\mathrm{C}-$ & 285.0 \\
\hline 2 & $-\mathrm{C}-\mathrm{OH},-\mathrm{C}-\mathrm{O}-\mathrm{C}-$ & 286.3 \\
\hline 3 & Bridged structure & 287.4 \\
\hline 4 & $\mathrm{C}=\mathrm{O},-\mathrm{COOR}$ & 288.9 \\
\hline
\end{tabular}

Table 4. Surface component analysis of C1s curve of different carbon fiber samples

\begin{tabular}{|l|c|c|c|c|}
\hline \multicolumn{1}{|c|}{ Sample } & $\begin{array}{c}\text { Peak 1 } \\
\text { Area } \\
{[\%]}\end{array}$ & $\begin{array}{c}\text { Peak 2 } \\
\text { Area } \\
{[\%]}\end{array}$ & $\begin{array}{c}\text { Peak 3 } \\
\text { Area } \\
{[\%]}\end{array}$ & $\begin{array}{c}\text { Peak 4 } \\
\text { Area } \\
{[\%]}\end{array}$ \\
\hline CF & 67.0 & 21.0 & 8.3 & 3.7 \\
\hline Rare earth treated CF & 58.5 & 25.9 & 10.6 & 5.0 \\
\hline
\end{tabular}

earth treatment, the content of $-\mathrm{C}-\mathrm{C}-$ decreased while the content of $-\mathrm{C}-\mathrm{OH},-\mathrm{C}-\mathrm{O}-\mathrm{C}-$, Bridged structure, $\mathrm{C}=\mathrm{O}$ and $-\mathrm{COOR}$ increased, which increased total surface energy and their polarity thus enhanced the wettability of the CF with the PI matrix. Better wetting can improve the adhesive bond strength by increasing the thermodynamic work of adhesion or by reducing the number of interfacial defects [17]. Adhesion between $\mathrm{CF}$ and PI matrix improved, which played an important 
role on the flexural strength and tribological properties of CF filled polymer composites.

\subsection{Flexual strength of PI composites}

The flexual strength of $\mathrm{CF}$ and rare earth treated $\mathrm{CF}$ filled PI samples was $193 \mathrm{MPa}, 212 \mathrm{MPa}$, respectively. It can be seen that the flexural strength of PI composite filled with the rare earth treated $\mathrm{CF}$ is improved by $10.4 \%$ compared with that with the untreated one. The strength of fiber reinforced composites strongly depends on the interfacial adhesion between fibers and matrix. When there is a strong adhesion between fibers and matrix, the load stress is efficiently transmitted from the matrix to fibers and the fibers can successfully carry the load, so the fiber can bring more reinforcement [18]. The rare earth treated CF filled PI composite had a higher flexual strength, which indicated that the rare earth treatment improved the interfacial adhesion between carbon fibers and PI matrix. Adhesion between CF and PI matrix improved, which played an important role on improving the tribological properties of $\mathrm{CF}$ reinforced polymer composites.

\subsection{The tribological property}

Figure 6 shows the friction coefficient and wear rate of untreated $\mathrm{CF} / \mathrm{PI}$ and rare earth treated $\mathrm{CF} / \mathrm{PI}$ composites at a sliding speed of $0.431 \mathrm{~m} / \mathrm{s}$ under $200 \mathrm{~N}$. It was found that the wear rate of the rare earth treated CF/PI composite decreased drastically than that of the untreated CF/PI composites, though the friction coefficient decreased slightly. It can be concluded that the reinforcement effect of the rare

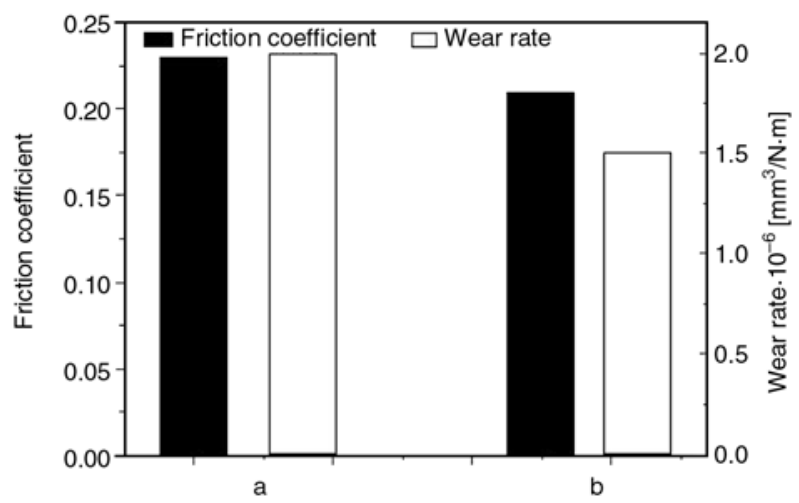

Figure 6. Variation of the friction coefficient and wear rate of the untreated $\mathrm{CF} / \mathrm{PI}$ (a) and rare earth treated CF/PI (b) composites $(0.431 \mathrm{~m} / \mathrm{s}$ and $200 \mathrm{~N}$ ) earth treated CF was better than that of the untreated one. The reason may be that the adhesion between $\mathrm{CF}$ and PI matrix improved greatly after rare earth treatment. An improved adhesion can transmit the load from the matrix to fibers efficiently and prevent the peeling off of $\mathrm{CF}$, which resulted in better tribological behaviors. However, the untreated CF can not bear the load efficiently and can be easily peeled off and there formed third body, which can result in serious abrasive wear to the surface of the PI composites in the friction process, which resulted in a higher friction coefficient and wear rate.

\section{Conclusions}

The rare earth treatment could increase the surface roughnesss thus formed more mechanical interlocking sites, which can improve the interfacial bonding. Moreover, the rare earth treatment could increase the $\mathrm{O} / \mathrm{C}$ ratio of the carbon fiber surface and lots of active functional groups formed there, which can improve the wettability by enhancing the surface energy and thus enhanced the interfacial bonding. In conclusion, the surface treatment favored the improvement of the higher interface strength and so had good effect on improving the tribological behaviors of the composites.

\section{Acknowledgements}

The authors would like to acknowledge the financial support of the Innovative Group Foundation from NSFC (Grant No. 50421502) and the National Natural Science Foundation of China (Grant No.50475128) and the important direction project for the knowledge innovative engineering of Chinese Academy of Sciences (Grant No. KGCX3-SYW-205).

\section{References}

[1] Bahadur S., Polineni V. K.: Tribological studies of glass fabric-reinforced polyamide composites filled with $\mathrm{CuO}$ and PTFE. Wear, 200, 95-104 (1996).

[2] Price D. M.: Vapor pressure determination by thermogravimetry. Thermochimica Acta, 367-368, 253-262 (2001).

[3] Okabe T., Takeda N.: Size effect on tensile strength of unidirectional CFRP composites -experiment and simulation. Composites Science and Technology, 62, 2053-2064 (2002). 
[4] Choi M. H., Jeon B. H., Chung I. J.: The effect of coupling agent on electrical and mechanical properties of carbon fiber/phenolic resin composites. Polymer, 41, 3243-3252 (2000).

[5] Varelidis P. C., McCullough R. L., Papaspyrides C. D.: The effect on the mechanical properties of carbon/epoxy composites of polyamide coatings on the fibers. Composites Science and Technology, 59, 1813-1823 (1999).

[6] Ogawa H., Satio K.: Oxidation behavior of polyacrylonitrile fibers evaluated by new stabilization index. Carbon, 33, 783-788 (1995).

[7] Wu Z. H., Pittman C. U., Gardner S. D.: Nitric acid oxidation of carbon fibers and the effects of subsequent treatment in refluxing aqueous $\mathrm{NaOH}$. Carbon, 33, 597-605 (1995).

[8] Toyoda M., Katoh H., Inagaki M.: Intercalation of nitric acid into carbon fibers. Carbon, 39, 2231-2237 (2001).

[9] Basova Y. V., Hatori H., Yamada Y., Miyashita K.: Effect of oxidation-reduction surface treatment on the electrochemical behavior of PAN-based carbon fibers. Electrochemistry Communications, 1, 540-544 (1999).

[10] Theodoridou E., Jannakoudakis A. D., Jannakoudakis P. D., Andonoglou P., Besenhard J. O.: Electrochemical oxidation of PAN- and pitch-based carbon fibers and deposition of palladium on the obtained materials. Synthetic Metals, 87, 225-229 (1997).
[11] Yue Z. R., Jiang W., Wang L., Gardner S. D., Pittman C. U.: Surface characterization of electrochemically oxidized carbon fibers. Carbon, 37, 1785-1796 (1999).

[12] Pittman C. U., Jiang W., Yue Z. R., Gardner S. D., Wang L.: Surface properties of electrochemically oxidized carbon fibers. Carbon, 37, 1797-1807 (1999).

[13] Wu G. M.: Oxygen plasma treatment of high performance fibers for composites. Materials Chemistry and Physics, 85, 81-87 (2004).

[14] Zhang X. R., Pei X. Q., Wang Q. H.: The effect of fiber oxidation on the friction and wear behaviors of short-cut carbon fiber/polyimide composites. Express Polymer Letters, 1, 318-325 (2007).

[15] Harris B., Braddell O. G., Almond D. P.: Study of carbon fibers surface treatment by dynamic mechanical analysis. Journal of Materials Science, 28, 3353-3366 (1993).

[16] Boudou J. P., Paredes J. I., Cuesta A., MartinezAlonso A., Tascon J. M. D.: Oxygen plasma modification of pitched-based isotropic carbon fibers. Carbon, 41, 41-56 (2003).

[17] Wu S.: Polymer interface and adhesion. Marcel Dekker, New York (1982).

[18] Choi M. H., Jeon B. H., Chung I. J.: The effect of coupling agent on electrical and mechanical properties of carbon fiber/phenolic resin composites. Polymer, 41, 3243-3252 (2000). 